\title{
Cam deformity and the omega angle, a novel quantitative measurement of femoral head-neck morphology: a 3D CT gender analysis in asymptomatic subjects
}

\author{
Vasco V. Mascarenhas ${ }^{1} \cdot$ Paulo Rego $^{2} \cdot$ Pedro Dantas $^{3} \cdot$ Augusto Gaspar $^{1} \cdot$ \\ Francisco Soldado $^{4}$ • José G Consciência ${ }^{5}$
}

Received: 25 April 2016 / Accepted: 21 July 2016/Published online: 30 August 2016

(C) European Society of Radiology 2016

\begin{abstract}
Objective Our objectives were to use 3D computed tomography $(\mathrm{CT})$ to define head-neck morphologic gender-specific and normative parameters in asymptomatic individuals and use the omega angle $\left(\Omega^{\circ}\right)$ to provide quantification data on the location and radial extension of a cam deformity.

Methods We prospectively included 350 individuals and evaluated 188 asymptomatic hips that underwent semiautomated CT analysis. Different thresholds of alpha angle $\left(\alpha^{\circ}\right)$ were considered in order to analyze cam morphology and determine $\Omega^{\circ}$. We calculated overall and gender-specific parameters for imaging signs of cam morphology $\left(\Omega^{\circ}\right.$ and circumferential $\left.\alpha^{\circ}\right)$. Results The $95 \%$ reference interval limits were beyond abnormal thresholds found in the literature for cam morphology. Specifically, $\alpha^{\circ}$ at $3 / 1$ o $^{\prime}$ clock were $46.9^{\circ} / 60.8^{\circ}$ overall, $51.8^{\circ} /$ $65.4^{\circ}$ for men and $45.7^{\circ} / 55.3^{\circ}$ for women. Cam prevalence, magnitude, location, and epicenter were significantly gender different. Increasing $\alpha^{\circ}$ correlated with higher $\Omega^{\circ}$, meaning that higher angles correspond to larger cam deformities.
\end{abstract}

Vasco V. Mascarenhas

mascarenhas.vasco@gmail.com

1 MSK imaging Unit (UIME), Imaging Center, Hospital da Luz, Lisbon, Portugal

2 Department of Orthopaedic Surgery, Hospital da Luz, Lisbon, Portugal

3 Hospital CUF Descobertas, Lisbon, Portugal

4 Hospital Sant Joan De Deu, Universitat De Barcelona, Barcelona, Spain

5 NOVA Medical School, Campo Mártires Pátria, Lisbon, Portugal
Conclusion Hip morphometry measurements in this cohort of asymptomatic individuals extended beyond current thresholds used for the clinical diagnosis of cam deformity, and $\alpha^{\circ}$ was found to vary both by gender and measurement location. These results suggest that $\alpha^{\circ}$ measurement is insufficient for the diagnosis of cam deformity. Enhanced morphometric evaluation, including $3 \mathrm{D}$ imaging and $\Omega^{\circ}$, may enable a more accurate diagnosis.

Key Points

- 95\% reference interval limits of cam morphotype were beyond currently defined thresholds.

- Current morphometric definitions for cam-type morphotype should be applied with care.

- Cam prevalence, magnitude, location, and epicenter are significantly gender different.

- Cam and alpha angle thresholds should be defined according to sex/location.

- Quantitative 3D morphometric assessment allows thorough and reproducible FAI diagnosis and monitoring.

Keywords Hip · Femoroacetabular impingement . Multidetector computed tomography $\cdot$ Reference value . Variant
Abbreviations
FAI Femoroacetabular impingement
FHN Femoral head/neck
OA Osteoarthritis
CT Computed tomography
MRI Magnetic resonance imaging
CR conventional X-ray 
$\Omega^{\circ} \quad$ Omega angle

$\alpha^{\circ} \quad$ Alpha angle

\section{Introduction}

Femoroacetabular impingement (FAI) is a common cause of hip pain and refers to the abnormal conflicting movement of the femoral head-neck (FHN) junction against the acetabular rim [1], eventually resulting in hip damage and osteoarthritis (OA) [2-4]. The cam type generally involves an FHN deformity and the pincer-type acetabular overcoverage [1]. There is a wide discrepancy in reported prevalence rates between cam and pincer FAI among asymptomatic and symptomatic and athletes [5, 6].

The diagnosis of FAI is made using a combination of clinical and imaging findings [7]. Different radiographic views using conventional X-rays (CR) have been tested for diagnostic utility in FAI [7, 8]. However, the reliability of twodimensional (2D) measurements has been questioned [9], since FHN morphology cannot be fully characterized using a single CR [9, 10].

Magnetic resonance imaging (MRI) [11] and computed tomography (CT) [12] allow reconstructions in multiple planes, providing a better understanding of the magnitude of the femoral morphology. However, CT/MRI standard techniques for measuring cam-type FAI still provide only a $2 \mathrm{D}$ characterization of FHN morphology, since measurements are made on a limited series of slices [13-15]. Morphological studies have demonstrated that the femoral head may be elliptical in shape with important interindividual variability. This variability may further contribute to significant variations in alpha angle $\left(\alpha^{\circ}\right)$ measurements and to related diagnostic limitations of oblique axial and multiple radialplane imaging protocols $[15,16]$.

The $\alpha^{\circ}$, the most frequently used parameter to grade cam morphology and describe the FHN junction, has been suggested as a predictor for the risk of anterior impingement and extent of cartilage defects $[17,18]$. However, an $\alpha^{\circ}$ measurement is performed in only one plane and so is highly dependent on the position at which it is measured [19]. Several authors have questioned the diagnostic accuracy and relevance of the $\alpha^{\circ}[20,21]$, as abnormally high $\alpha^{\circ}$ values have been reported in asymptomatic individuals [6] and amazingly normal threshold values to diagnose cam deformities may range from $50^{\circ}$ to $82^{\circ}[17,21-24]$. Studies using these reference intervals to identify cam deformities have demonstrated a risk for false-positive results when applying these thresholds [15, 25, 26].

Accurately understanding the 3D spatial characteristics of cam deformities is of paramount importance not only for diagnosis but also for optimal treatment planning. Current 2D imaging protocols for FAI do not permit complete consideration of these features. The radial extension of cam deformity has been described using MRI to compare bone resection using different surgical techniques [27], but 3D imaging might provide more accurate estimates. However, the optimal method for using 3D CT in this setting has not been well defined. In addition, we lack normative data with regard to 3D morphology of the FHN in asymptomatic individuals. A predictable and accurate method for evaluating femoral morphology is needed to optimize surgical results and minimize complications [28].

To our knowledge, no previous study has evaluated 3D radial circumference of the FHN in a cohort of young, asymptomatic patients. The purpose of this study in a cohort of asymptomatic individuals was to:(a) characterize FHN morphology using angular measurements taken from 3D CT images; (b) estimate overall and gender-specific normative ranges for $3 \mathrm{D}$ angular measurements of the FHN junction; and (c) use 3D angular measurements, namely, the omega angle $\left(\Omega^{\circ}\right)$, to quantify the location and extent of cam lesions.

\section{Methods}

\section{Study population}

Institutional ethics committee approval was obtained prior to beginning this study, and all participants provided written informed consent. We prospectively recruited consecutive adult patients undergoing pelvic CT at our institution for thoracic, abdominal, or urogenital indications from August to December 2015. All eligible participants completed a questionnaire regarding their clinical history, including current or past hip/groin pain, medical or surgical hip-joint conditions, history of childhood hip pathology, and/or hip trauma. Patients who gave a positive answer to one or more of these questions were excluded. Additionally, all patients completed the nonarthritic hip score (NAHS) questionnaire [29]. Any patient with less than the maximum possible score was also excluded.

In all, 350 hips were potentially eligible for analysis. We then excluded all patients with CT signs of OA, defined as the presence of at least one of the following findings [30]: joint-

Table 1 Characteristics of included and excluded individuals

\begin{tabular}{|c|c|c|c|}
\hline & Number $^{\mathrm{a}}$ & Age $\pm \mathrm{SD}(\text { years-old })^{\mathrm{b}}$ & Range \\
\hline Total included patients & 94 & $34.8 \pm 7.2$ & $18-44$ \\
\hline Male & 49 & $35.0 \pm 8.2$ & $18-44$ \\
\hline Female & 45 & $34.4 \pm 5.2$ & $23-44$ \\
\hline Total excluded patients & 256 & $40.0 \pm 4.2$ & $18-46$ \\
\hline
\end{tabular}


Fig. 1 Reformatted 3D computed tomography $(\mathrm{CT})$ images and corresponding 3D hip model in a 36-year-old man. Oblique axial (a, b), short-axis image at femoral head/neck junction $(\mathbf{c}, \mathbf{d})$, and oblique coronal (e, f) imaging used to determine 12-o'clock position according to the protocol proposed by Philippon et al [33] (g). Red line represents central neck axis
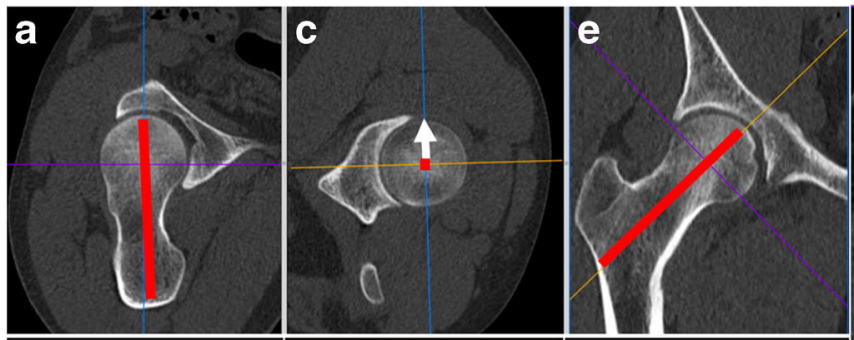

g
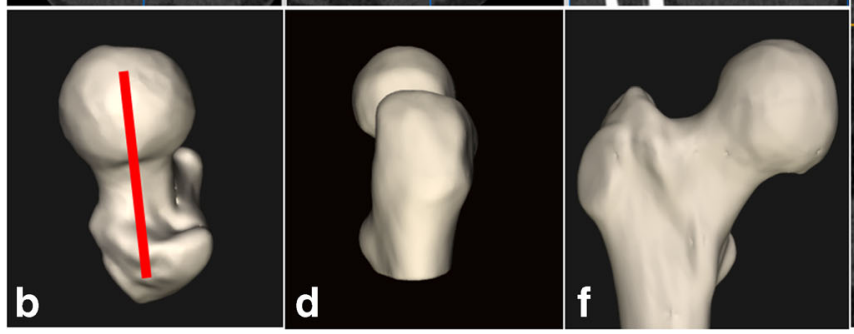

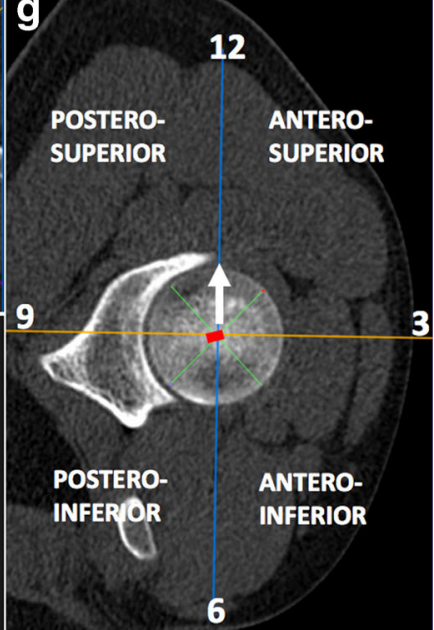

space narrowing, osteophytes, or subchondral bone changes, including sclerosis or cysts. Finally, we excluded hips with any other diagnosed abnormalities on CT: fracture, posttraumatic deformity, Perthes disease, osteonecrosis, slipped capital femoral epiphysis, dysplasia (lateral center-edge angle $<20^{\circ}$ ), or bone lesions (Table 1). In total, 188 hips in 94 patients met criteria for inclusion in the final analysis.

\section{CT imaging}

CT imaging was performed using a Somatom Sensation 64slice CT scanner (Siemens, Erlangen, Germany). Patients were positioned in a standard supine position with legs parallel in neutral rotation and patellae pointing directly upward. The pelvis was reconstructed from the anterior superior iliac
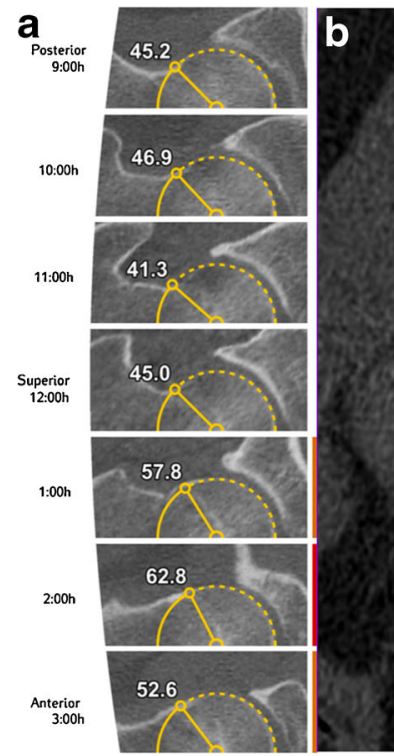

Fig. 2 Alpha-angle $\left(\alpha^{\circ}\right)$ measurements made at different points around the femoral head/neck junction in steps of $1^{\circ}$ starting at 9 o'clock (posterior); 10, 11, and 12 o'clock (superior); and 1, 2, and 3 o'clock (anterior) (a).Femoral short-axis computed tomography (CT) reformat derived from Fig. 1 shows bone contour abnormality from 12- to 3o'clock [omega angle $\left(\Omega^{\circ}\right)$ of $91^{\circ}$ ]. The $\Omega^{\circ}$ is formed by two lines intersecting the center of the femoral neck at the level of the head/neck junction. The most proximal line intersects peripherally the point at which the $\alpha^{\circ}$ begins to be abnormal beyond a best-fitting circle and the distal line at the point where the $\alpha^{\circ}$ returns to normal (b). Polar plot (2D) of the

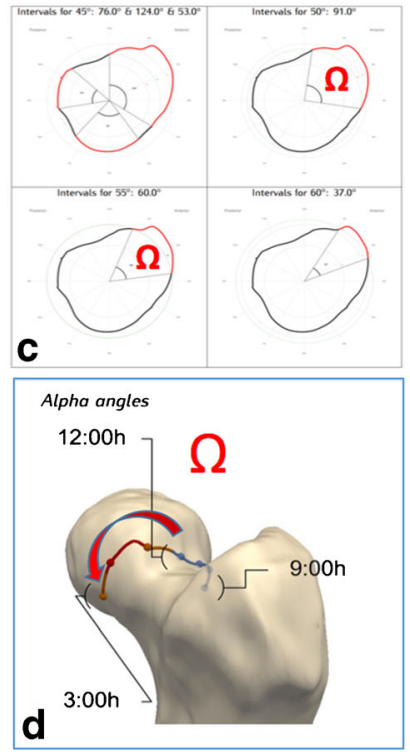

$360^{\circ} \alpha^{\circ}$, representing the $\Omega^{\circ}$ angle (red symbol) for different $\alpha^{\circ}$ thresholds $\left[45^{\circ}\right.$ (upper left), $50^{\circ}$ (upper right), $55^{\circ}$ (lower left), $60^{\circ}$ (lower right)]. Red lines represent increased $\alpha^{\circ} \mathrm{s}$ for a given threshold (c). Hip model (3D) showing extension and location of a cam lesion represented on the corresponding 3D model (red arrow). The $\Omega^{\circ}$ measures the amount of linear radial extension of a cam deformity corresponding to the angular measurement of the red arrow. Red and orange lines correspond to abnormal $\alpha^{\circ} \mathrm{s}$; blue line represent normal $\alpha^{\circ}$ s for a given $\alpha$ threshold 
Table 2 Mean alpha angles $\left(\alpha^{\circ}\right)$, standard deviation (SD), and upper limit of $95 \%$ of confidence interval $(\mathrm{CI})$ at each clock-face position (all participants)

\begin{tabular}{|c|c|c|c|c|}
\hline & $\begin{array}{l}\text { Plane orientation } \\
\text { by clock face }\end{array}$ & All alpha angles ${ }^{\mathrm{a}}$ & SD & Upper limit of $95 \% \mathrm{CI}^{\mathrm{a}}$ \\
\hline \multirow[t]{6}{*}{ Posterosuperior } & 9 & 44.9 & 4.3 & 45.8 \\
\hline & $9: 30$ & 45.6 & 3.5 & 46.3 \\
\hline & 10 & 45.2 & 3.7 & 46.0 \\
\hline & $10: 30$ & 43.8 & 3.7 & 44.6 \\
\hline & 11 & 42.6 & 3.4 & 43.3 \\
\hline & $11: 30$ & 43.4 & 3.4 & 44.1 \\
\hline \multirow[t]{6}{*}{ Anterosuperior } & 0 & 47.8 & 6.7 & 49.2 \\
\hline & $0: 30$ & 54.1 & 9.2 & 56.0 \\
\hline & 1 & 58.9 & 8.8 & 60.8 \\
\hline & $1: 30$ & 58.9 & 6.8 & 60.3 \\
\hline & 2 & 54.9 & 5.5 & 56.1 \\
\hline & $2: 30$ & 50.8 & 4.9 & 51.2 \\
\hline \multirow[t]{6}{*}{ Anteroinferior } & 3 & 45.8 & 4.9 & 46.9 \\
\hline & $3: 30$ & 42.7 & 4.4 & 43.6 \\
\hline & 4 & 41.7 & 3.6 & 42.4 \\
\hline & $4: 30$ & 42.8 & 3.5 & 43.5 \\
\hline & 5 & 45.2 & 3.6 & 46.0 \\
\hline & $5: 30$ & 48.2 & 3.5 & 48.9 \\
\hline \multirow[t]{6}{*}{ Posteroinferior } & 6 & 49.3 & 3.3 & 50.0 \\
\hline & $6: 30$ & 48.1 & 3.5 & 48.9 \\
\hline & 7 & 46.0 & 3.7 & 46.8 \\
\hline & $7: 30$ & 44.2 & 3.9 & 45.0 \\
\hline & 8 & 43.8 & 4.2 & 44.7 \\
\hline & $8: 30$ & 44.5 & 4.2 & 45.4 \\
\hline
\end{tabular}

${ }^{\mathrm{a}}$ Mean

spines to the lesser trochanters, with 1-mm thickness. Patients received no additional radiation during imaging beyond that required for the CT studies ordered to evaluate their specific medical conditions.

\section{Three-dimensional model}

Digital Imaging and Communications in Medicine (DICOM) images were uploaded for analysis using Articulis (Articulis ${ }^{\mathrm{TM}}$; Clinical Graphics, Delft, The Netherlands) and semiautomatically segmented using this software, which had been previously validated for reliability and accuracy [31]. For each hip, nonradiodense structures were digitally subtracted, rendering a $3 \mathrm{D}$ image of a hemipelvis containing the left or right hip. Two experienced radiologists (VVM and AG) checked whether each segmentation contained all osseous contours of the CT scan.

\section{Omega angle}

To determine the $\Omega^{\circ}$ (Figs. 1 and 2), we calculated the clockwise $360^{\circ}, \alpha^{\circ}$ by using a regression sphere fit of the FHN junction [32]. The $\alpha^{\circ}$ was calculated according to method 1 described by Nötzli et al. [17]. The first angle was obtained using a measurement plane defined by the femoral neck axis and a vector perpendicular to this axis pointing upward to define a superior 12 o'clock position [33] (Fig. 1). For subsequent measurement planes, this vector was rotated around the femoral neck in steps of $1^{\circ}$, leading to measurement of the $360^{\circ} \alpha^{\circ}$. An automated algorithm based on radial sequences was then used to determine the maximum $\alpha^{\circ}$ and its location (Fig. 2a). Two radiologists (VVM and AG) reviewed the images to confirm plausibility of computer-determined measurements. Next, projecting the $360 \alpha^{\circ}$ in a polar plot (Fig. 2c), we found the $\Omega^{\circ}$ by measuring the angle corresponding to the three points formed by the center of the femoral head, the point where the $\alpha^{\circ}$ exceeds a determined threshold value and the last one where the $\alpha^{\circ}$ returns to a normal value (Figs. $2 \mathrm{~b}$ and c). We used $45,50,55$, and $60^{\circ}$ as $\alpha^{\circ}$ thresholds for measuring different $\Omega^{\circ}$ values (Fig. 2c). This automated analysis yielded measurements of cam magnitude (determined by the $360^{\circ} \alpha^{\circ}$ and $\Omega^{\circ}$ ) and cam location (mapped on the previously defined clock face system, both in 2D maps and 3D models) (Fig. 2c and d). 
Fig. 3 Evaluation of femoral head/neck (FHN) morphology. Three-dimensional model in four projections: top row (left to right), anterior and anterosuperior views; bottom row (left to right), superior and posterior views.

Corresponding 2D map of mean circumferential alpha angles $\left(\alpha^{\circ}\right)$ at every degree for all participants: 0 12-o'clock position; $89^{\circ} 3$-o'clock position

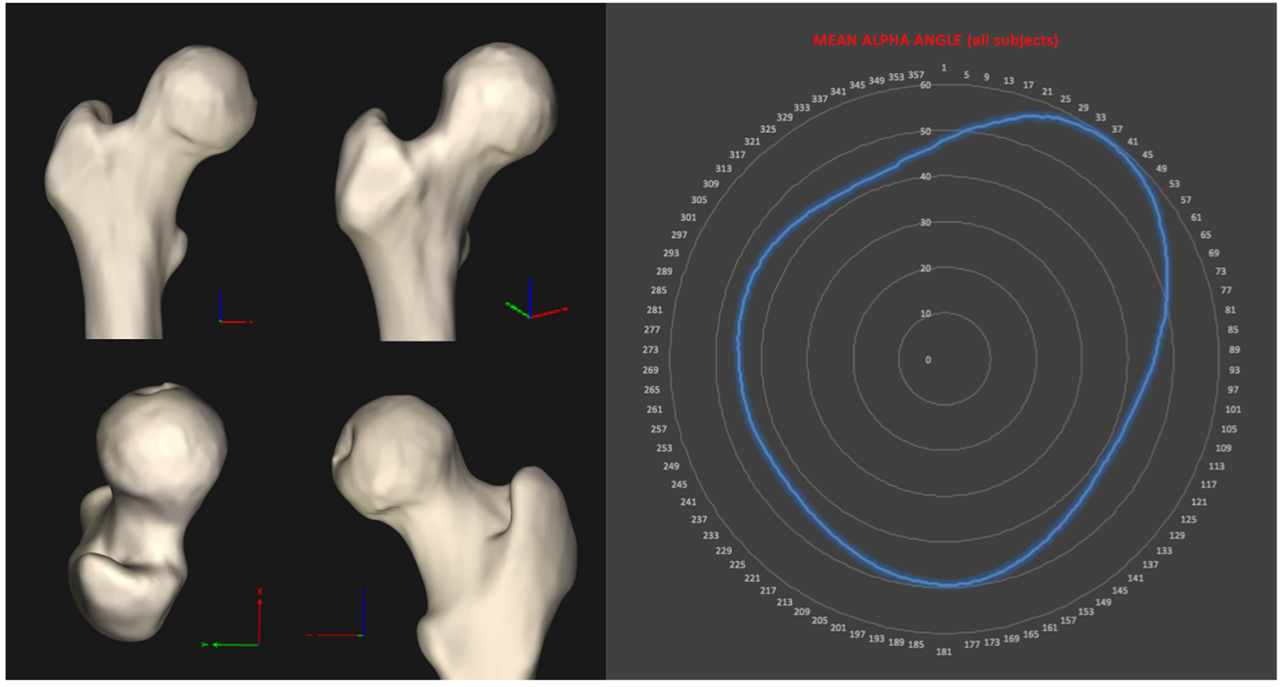

\section{Statistical analysis}

For all morphometric parameters, mean values, standard deviations (SD), and double-sided $95 \%$ reference intervals were calculated. Quantitative parameters are described by their average and SD. Qualitative parameters are described in numbers and percentage. For the average comparison, Student's $t$ test was implemented to compare quantitative variables. If test conditions were not met, a nonparametric test was used. To evaluate correlation between two quantitative parameters, Pearson or Spearman coefficients were computed. A $p$ value of 0,05 was considered statistically significant for all analyses. Statistical analyses were performed using dedicated software (MedCalc Software version 11.6; Belgium).

\section{Results}

Images were obtained for 188 hips from 94 patients (age range $18-44 ; 49$ men and 45 women) (Table 1 ). Measured $\alpha^{\circ}$ ranged from $45^{\circ}$ to $75^{\circ}$, with an overall mean maximal $\alpha^{\circ}$ of $59.5^{\circ}$ at 1:14 o'clock. Of the 188 hips, 182 demonstrated at least one elevated $\alpha^{\circ}$ value at any single clock-face segment when using an $\alpha^{\circ}$ threshold of $50^{\circ}$. The mean elevated $\alpha^{\circ}$ measurement was $60.5^{\circ}$ (range 50.1-80.3 ${ }^{\circ}$ (Table 2 and Fig. 3).

The presence of a cam deformity was defined as an increased $\alpha^{\circ}$ for at least three consecutive points of measurement. Applying $\alpha^{\circ}$ thresholds of $50^{\circ}, 55^{\circ}$, and $60^{\circ}$, cam deformity was identified in 182,148 , and 90 hips, respectively, out of 188 (Fig. 4).

The clock-face position at which $\alpha^{\circ}$ was most frequently elevated was 1 and 1:30 o'clock (respectively: frequency of raised $\alpha^{\circ}=82$ and 87; frequency of location of largest $\alpha^{\circ}=32$ vs 35). The involved clock-face segments ranged between 0 and 6 ; mean of the $\alpha^{\circ}$ measurements at each clock-face position was greatest at the $1: 30$ position $\left(58.9^{\circ} \pm 6.8\right.$; range $\left.46.4-76.4^{\circ}\right)$ and at $1 \mathrm{o}^{\prime}$ clock $\left(58.9^{\circ} \pm 8.8\right.$; range $\left.41.6-80.3^{\circ}\right)$ (Table 3).

Sex differences were observed by the presence, magnitude, and location of cam deformities. Overall cam prevalence was higher in men for any threshold of $\alpha^{\circ}(p<0,01)$, as was maximal mean $\alpha^{\circ}\left(63.63^{\circ}\right.$ vs $\left.55.74^{\circ} ; p<0,001\right)$. Sex-different $\alpha^{\circ}$ measurements were notably significant at $1: 30$ (men vs women $61.79^{\circ}$ vs $55.73^{\circ}, p<0.001$ ), at 1:00 (men vs women $63.5^{\circ}$ vs $\left.53.3^{\circ}, p<0.001\right)$, and at $10-10: 30 \mathrm{o}^{\prime}$ clock ( $p=0.042)$ (Table 4 and Fig. 5)

Mean cam magnitude, defined by the radial extension of the deformity, was significantly greater in men (from $0-2 \mathrm{~h}$ 32 min vs 0 h 36 min -2 h 28 min; $p=0.01$ ). Mean epicenter of the cam deformity was located significantly more superiorly in the anterosuperior quadrant for men compared with women ( 1 h 04 min vs 1 h 32 min; $p<0.001$ ) (Table 5 and Fig. 6).

Mean angular range of radial extension of involved segments was translated by a mean $\Omega^{\circ}$. The $\Omega^{\circ}$ for a $50^{\circ}$ and $55^{\circ}$, $\alpha^{\circ}$ threshold was, respectively, $65^{\circ} \pm 25$ (men vs women $71^{\circ}$ vs $57^{\circ}, p=0.02$ ) and $35^{\circ} \pm 24$ (men vs women $43^{\circ}$ vs $25^{\circ}$, $p=0,03$ ) (Table 5). Significant positive correlations were seen

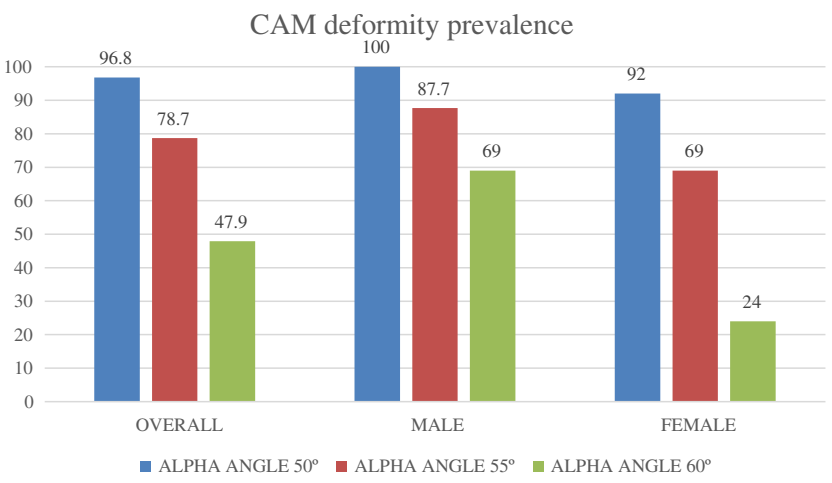

Fig. 4 Cam deformity prevalence: overall participants and gender-specific breakdown by different alpha angle $\left(\alpha^{\circ}\right)$ thresholds $\left(50,55\right.$, and $\left.60^{\circ}\right)$ 
Table 3 Frequency and mean increased alpha angles $\left(\alpha^{\circ}\right)$ at each clock-face position in 188 hips. Location of largest alpha angles recorded at each position, mean range of deformity (radial extension), and mean epicenter (point of highest $\alpha^{\circ}$ ) also shown

\begin{tabular}{|c|c|c|c|c|c|c|c|}
\hline & $\begin{array}{l}\text { Plane orientation by } \\
\text { clock-face position }\end{array}$ & $\begin{array}{l}\text { Increased alpha } \\
\text { angle }^{\mathrm{a}} \text { (for } 50^{\circ} \\
\text { threshold) }\end{array}$ & Range $^{a}$ & $\begin{array}{l}\text { Frequency of } \\
\text { raised alpha } \\
\text { angle }^{\mathrm{b}}\end{array}$ & $\begin{array}{l}\text { Location of } \\
\text { largest alpha } \\
\text { angle }^{b}\end{array}$ & $\begin{array}{l}\text { Range of deformity } \\
\mathrm{a} \text { (radial extension) }\end{array}$ & $\begin{array}{l}\text { Epicenter of } \\
\text { deformity }^{\mathrm{c}}\end{array}$ \\
\hline \multirow[t]{6}{*}{ Posterosuperior } & 9 & 51 & $50.3-53.9$ & 10 & 0 & \multirow[t]{13}{*}{$0: 10^{\prime}-2: 30^{\prime}$} & \multirow[t]{13}{*}{$1: 14^{\prime} \pm 6^{\prime}$} \\
\hline & $9: 30$ & 51.4 & $50.1-52.2$ & 10 & 0 & & \\
\hline & 10 & 51.5 & $50.2-55.3$ & 12 & 0 & & \\
\hline & $10: 30$ & 51.3 & $50.2-52.5$ & 12 & 0 & & \\
\hline & 11 & 51 & $51-51$ & 2 & 0 & & \\
\hline & $11: 30$ & 52 & $50.4-52$ & 10 & 0 & & \\
\hline \multirow[t]{7}{*}{ Anterosuperior } & 0 & 56.4 & $50.1-77$ & 40 & 2 & & \\
\hline & $0: 30$ & 58.2 & $50.2-81.9$ & 122 & 8 & & \\
\hline & 1 & 60.5 & $50.1-80.3$ & 164 & 35 & & \\
\hline & $1: 30$ & 58.9 & $46.4-76.4$ & 174 & 36 & & \\
\hline & 2 & 55 & $39.3-71$ & 154 & 11 & & \\
\hline & $2: 30$ & 53.9 & $50.1-65.3$ & 92 & 1 & & \\
\hline & 3 & 53.8 & $50.2-59.1$ & 30 & 1 & & \\
\hline
\end{tabular}

${ }^{\mathrm{a}}$ Mean

${ }^{\mathrm{b}}$ Absolute count

${ }^{\mathrm{c}}$ Mean \pm standard deviation

between $\Omega^{\circ}$ and $\alpha^{\circ}$ for all thresholds of $\Omega^{\circ}$ and locations of $\alpha^{\circ}$ measurements (increasing values of $\alpha^{\circ}$ significantly corresponded to higher values of $\Omega^{\circ}$ ) (Table 6).

\section{Discussion}

There is a need for improved techniques and criteria to identify and treat FAI [34]. Considering the strong association between cam FAI and OA [2], the ongoing debate in the literature on criteria for an imaging diagnosis of FAI is of paramount importance. Prior studies have used different cutoff values for morphometric parameters of cam FAI [7, 17, 21, 23-25, 30, 35-44, ] (Table 7). Accordingly, recent studies have pointed out the high prevalence of radiographic findings suggestive of FAI in asymptomatic populations [6] when applying currently used diagnostic thresholds, emphasizing the need for re-evaluation of these cutoffs [36, 45-47].

In our asymptomatic cohort, we found that the measured cam morphometry values extended beyond commonly used
Table 4 Mean of all alpha angles $\left(\alpha^{\circ}\right)$, range, and standard deviation (SD) at each clock-face position in 188 hips. Mean male/female $\alpha^{\circ}$ and corresponding statistical difference recorded at each position also shown

\begin{tabular}{lllllll}
\hline & $\begin{array}{l}\text { Plane orientation } \\
\text { by clock face }\end{array}$ & $\begin{array}{l}\text { All alpha } \\
\text { angles }^{\mathrm{a}} \pm \mathrm{SD}\end{array}$ & Range $^{\mathrm{a}}$ & Male $^{\mathrm{a}}$ & Female $^{\mathrm{a}}$ & $\begin{array}{l}P \text { value } \\
(t \text { test })\end{array}$ \\
\hline Posterosuperior & 9 & $44.9 \pm 4.3$ & $23.2-53.9$ & 44.6 & 45.1 & $\mathrm{NS}$ \\
& $9: 30$ & $45.6 \pm 3.5$ & $36.5-52.2$ & 45.2 & 46 & $\mathrm{NS}$ \\
& 10 & $45.2 \pm 3.7$ & $35.5-55.5$ & 44.4 & 46.1 & 0.043 \\
& $10: 30$ & $43.8 \pm 3.7$ & $35.7-52.5$ & 42.7 & 45.1 & 0.042 \\
& 11 & $42.6 \pm 3.4$ & $34.7-51$ & 42.1 & 43.1 & $\mathrm{NS}$ \\
& $11: 30$ & $43.4 \pm 3.4$ & $35.4-52$ & 44 & 42.7 & $\mathrm{NS}$ \\
& 0 & $47.8 \pm 6.7$ & $37.1-77$ & 50.4 & 44.8 & $<0.001$ \\
& $0: 30$ & $54.1 \pm 9.2$ & $36.9-81.9$ & 58.6 & 49.1 & $<0.001$ \\
& 1 & $58.9 \pm 8.8$ & $41.6-80.3$ & 63.5 & 53.3 & $<0.001$ \\
& $1: 30$ & $58.9 \pm 6.8$ & $46.4-76.4$ & 61.8 & 55.7 & $<0.001$ \\
& 2 & $54.9 \pm 5.5$ & $39.3-71$ & 56.2 & 53.6 & 0.032 \\
& $2: 30$ & $50.8 \pm 4.9$ & $38.2-65.3$ & 50.4 & 49.9 & $\mathrm{NS}$ \\
& 3 & $45.8 \pm 4.9$ & $35-59.1$ & 45.9 & 45.8 & $\mathrm{NS}$ \\
\hline
\end{tabular}

NS not significant

${ }^{a}$ Mean 
Fig. 5 Alpha angle $\left(\alpha^{\circ}\right)$ measurement comparison by gender at each clock-face position. Statistically significant differences are marked by the corresponding $p$ value

\section{Gender alpha angle Clock Face comparison}

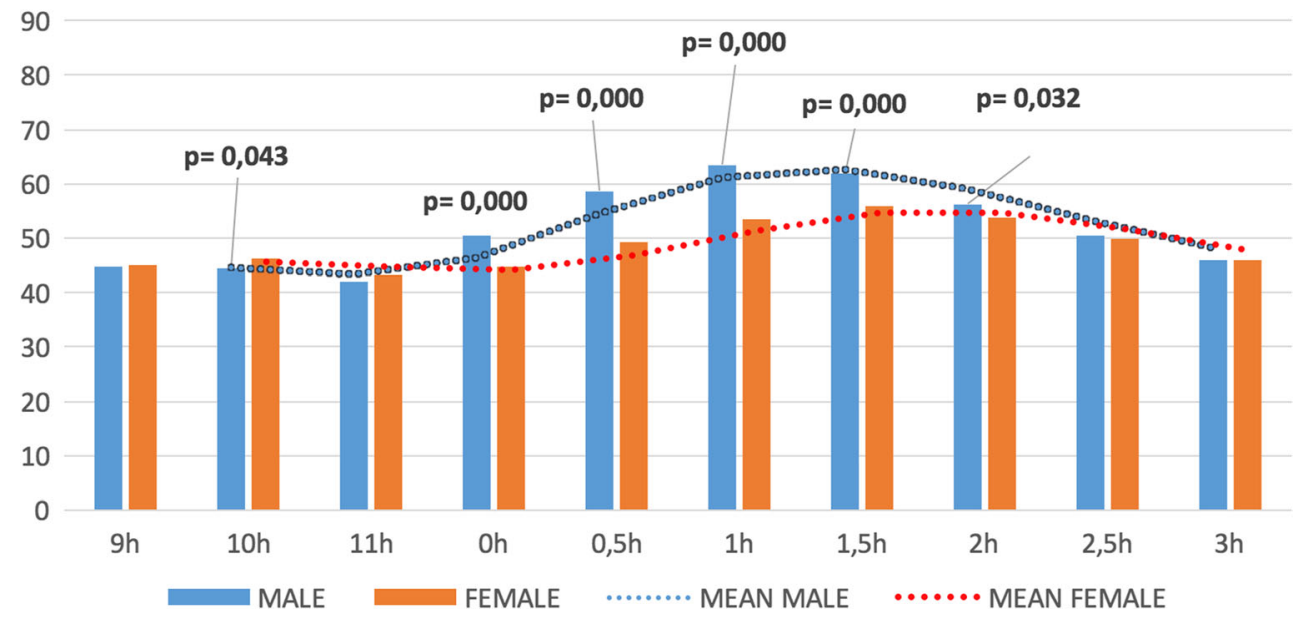

thresholds for the diagnosis of cam deformity. For example, upper limits of reference intervals calculated for $\alpha^{\circ}$ at 3/1:30 were $46.8^{\circ} / 60.3^{\circ}$. Previously, Sutter et al. [21] found the highest $\alpha^{\circ}$ measurements at the anterosuperior quadrant to be $55.0^{\circ} \pm 8.8$, and $\alpha^{\circ}>55^{\circ}$ in $38-62 \%$ of asymptomatic volunteers. Our study found the highest $\alpha^{\circ}$ measurements to be $58.9^{\circ} \pm 6.8$, and almost $78 \%$ were found to have an $\alpha^{\circ}>55^{\circ}$.

Also, we found normative data similar to the $50^{\circ}$ thresholds previously proposed at 3 o'clock by Nötzli et al. [17] and at 1:30 by Lepage-Saucier et al. [30], but our measurements were globally higher at the anterosuperior quadrant compared with most other studies [21,35]. In a recent review, cam-type morphology was found in $22.4 \pm 6.2 \%$ of all asymptomatic individuals [6]. In contrast, in this study, we found a higher prevalence of cam morphology, reaching $78.7 \% / 48.9 \%$ for $55^{\circ} / 60^{\circ} \alpha^{\circ}$ thresholds, respectively. Similarly to findings in our study, however, in a study using radial MRI, Reichenbach et al. [45] found that $73.3 \%$ of asymptomatic cases showed some evidence of a cam-type deformity.

In regards to cam location and magnitude, our study confirms that in an asymptomatic cohort, the deformity was most prominent in the anterosuperior FHN junction and extended around a significant radial extent. The most common position in which we found the largest $\alpha^{\circ}$ and a raised $\alpha^{\circ}$ coincided with 1 and 1:30 o'clock on the clock face. These results are generally consistent with findings of other studies [11, 48], although slightly superior to the anterosuperior quadrant 2 o'clock position defined by Khan et al. [49].

Including measurement of $\Omega^{\circ}$ to define cam radial location and extension permits better characterization of cam deformity. In this study, greater $\alpha^{\circ}$ was found to correlate with increasing $\Omega^{\circ}$. We found a mean increase in $\alpha^{\circ}$ measurements of $60.5^{\circ}\left(50.1-80.3^{\circ}\right)$ compared with $64.6^{\circ}\left(50.8-86^{\circ}\right)$ in a symptomatic cohort using a similar methodology [49]. In that study, the arc of cam deformity ranged between $60^{\circ}$ and $90^{\circ}$ [49], but our study found lower magnitudes (mean $\Omega^{\circ} 65^{\circ}$ ), as would be expected in an asymptomatic cohort. This is an area for further application of the $\Omega^{\circ}$ technique, enabling detailed subgroup analysis.

Some variation between our results and previously reported values might be explained by the heterogeneity of imaging methods employed, different locations of $\alpha^{\circ}$ measurements,

location of cam deformity). Significant gender differences are marked with an asterisk $(*)$

Table 5 Overall evaluation and by gender of magnitude and location of cam deformities: mean omega angles for different alpha-angle thresholds (range in brackets), mean range of deformity, and mean epicenter (peak

\begin{tabular}{|c|c|c|c|c|c|}
\hline & $\begin{array}{l}\text { Omega angle }\left(50^{\circ}\right. \\
\text { alpha angle threshold })\end{array}$ & $\begin{array}{l}\text { Omega angle }\left(55^{\circ}\right. \\
\text { alpha angle threshold })\end{array}$ & $\begin{array}{l}\text { Omega angle }\left(60^{\circ}\right. \\
\text { alpha angle threshold })\end{array}$ & $\begin{array}{l}\text { Range of cam deformity } \pm S D \\
\left(50^{\circ} \text { alpha angle threshold }\right)\end{array}$ & $\begin{array}{l}\text { Epicenter position (mean } \\
\text { alpha angle at epicenter) }\end{array}$ \\
\hline Overall & $\begin{array}{l}65^{\circ} \\
\left(0-179^{\circ}\right)\end{array}$ & $\begin{array}{l}35^{\circ} \\
\left(0-89^{\circ}\right)\end{array}$ & $\begin{array}{l}17^{\circ} \\
\left(0-84^{\circ}\right)\end{array}$ & $0: 10^{\prime}-2: 30^{\prime} \pm 6^{\prime}$ & $\begin{array}{l}1: 14^{\prime} \\
\left(59.5^{\circ}\right)\end{array}$ \\
\hline Male & $\begin{array}{l}71^{\circ} \\
\left(24-179^{\circ}\right)^{*}\end{array}$ & $\begin{array}{l}43^{\circ} \\
\left(0-89^{\circ}\right)^{* *}\end{array}$ & $\begin{array}{l}27^{\circ} \\
(0-84)^{* * *}\end{array}$ & $0: 00-2: 32^{\prime} \pm 9^{\prime * * * * *}$ & $\begin{array}{l}1: 04^{\prime} \\
\left(63.6^{\circ}\right) * * * * *\end{array}$ \\
\hline Female & $\begin{array}{l}57^{\circ} \\
\left(0-107^{\circ}\right)^{*}\end{array}$ & $\begin{array}{l}25^{\circ} \\
\left(0-66^{\circ}\right)^{* *}\end{array}$ & $\begin{array}{l}5^{\circ} \\
(0-44)^{* * * *}\end{array}$ & $0: 36^{\prime}-2: 28^{\prime} \pm 4^{\prime} * * * *$ & $\begin{array}{l}1: 32 \\
\left(55.7^{\circ}\right) * * * * *\end{array}$ \\
\hline
\end{tabular}

$S D$ standard deviation

$* p=0,02, * * p=0.03, * * * p=0.04, * * * * p=0.01, * * * * * p<0.001$ 


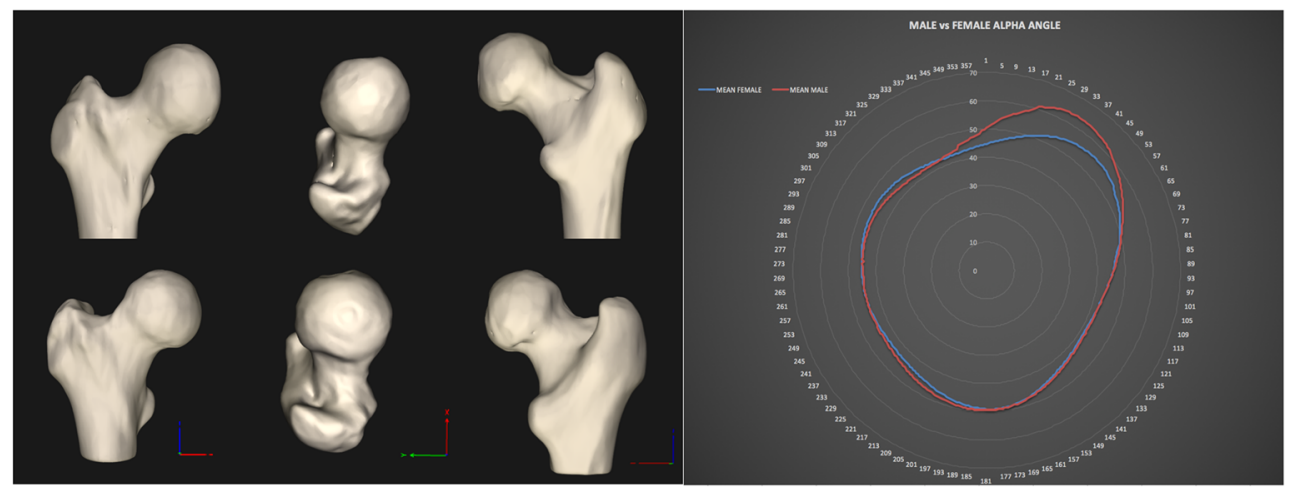

Fig. 6 Femoral head/neck (FHN) morphology by gender. Threedimensional model in three projections: top row female model (left to right), anterior, superior, and posterior views; bottom row male model (left to right), anterior, superior, and posterior views) and corresponding 2D map of mean circumferential alpha angles $\left(\alpha^{\circ}\right)$ at every degree (red line men; blue line women; 0 12-o'clock position, $89^{\circ} 3$-o'clock position) and - most importantly - nonstandardized definitions of what a cam deformity is $[23,35,50]$. Although $3 \mathrm{D}$ imaging can identify larger $\alpha^{\circ}$ than 2D imaging, these differences are mainly the result of measurement location [19]. Furthermore, there is an increased risk of residual impingement and vascular insult resulting from surgical treatment based on inaccurate data regarding the extent of deformities [27, 28, 51].

Intervals for the $\alpha^{\circ}$ were significantly different between genders, coherent with results reported by Hack et al. [35] but divergent from other studies [25, 30] (Table 7). Similarly, cam location varied significantly according to sex, in agreement with Ito et al. [52] but divergent from the study by Yanke et al. [53] (in symptomatic individuals). We also found that mean magnitude, location, and the epicenter of cam morphology were significantly gender different: in men, we specifically found larger cam radial extension, higher maximal mean increased $\alpha^{\circ}\left(63.63^{\circ}\right.$ vs $\left.55.74^{\circ}\right)$ and epicenter superiorly located in the anterosuperior quadrant (1 vs 1:30 o'clock). Also, Yanke et al. [53] found that cam magnitude was sex different, with deformities in men being significantly larger. Interestingly, at the posterosuperior quadrant (10/10:30 o'clock), we found surprisingly higher $\alpha^{\circ} \mathrm{s}$ in women. To our knowledge, this finding has not been described in the literature.
Importantly, the increased span of male compared with female deformities increases the likelihood of falsenegative 2D evaluations in women [53]. We hypothesize that pelvic morphology and other dynamic factors, such as distinct sports activities, increased female flexibility, pelvic rotation, or forward tilt from weaker core muscles contribute to these overall differences [53-55].

Prevalence of cam morphology using current thresholds and the width of reference intervals found in our study suggest that the currently used criteria for camtype FAI need to be revisited. More specifically, our results stress that the $\alpha^{\circ}$ alone is not an appropriate parameter to define cam lesions and that thresholds should be redefined according to sex and cam location. In recent $\mathrm{CT}$-based studies, 3D bone reconstructions of the proximal femur have been used to evaluate femoral head sphericity using $\alpha^{\circ}$ measurements [12, 34] and model fitting $[56,57]$. However, normative data is lacking on 3D CT morphology of the femoral head in asymptomatic individuals.

Therefore, we believe that our approach improves previously described hip-imaging methods for FAI by including measures of both deformity magnitude and location [11, 14, 58]. The use of 3D CT to directly visualize and quantify $3 \mathrm{D}$ morphology of the FHN junction permits detailed and

Table 6 Nonparametric bivariate correlation between different quantitative variables: alpha angle at different clock-face positions and omega angle with different $\alpha^{\circ}$ thresholds. Significant correlations are marked with an asterisk (*)

\begin{tabular}{|c|c|c|c|c|}
\hline Spearman's rho (significance) & $\begin{array}{l}\text { Alpha angle } \\
\text { at } 0: 00 \text { o'clock }\end{array}$ & $\begin{array}{l}\text { Alpha angle } \\
\text { at 1:00 o'clock }\end{array}$ & $\begin{array}{l}\text { Alpha angle } \\
\text { at 2:00 'clock }\end{array}$ & $\begin{array}{l}\text { Alpha angle } \\
\text { at 3:00 o'clock }\end{array}$ \\
\hline Omega angle (alpha angle threshold of $50^{\circ}$ ) & $0.75 * *$ & $0.71 * *$ & $0.76^{* *}$ & $0.60 * *$ \\
\hline Omega angle (alpha angle threshold of $55^{\circ}$ ) & $0.76^{* *}$ & $0.80 * *$ & $0.77 * *$ & $0.47 * *$ \\
\hline Omega angle (alpha angle threshold of $60^{\circ}$ ) & $0.71 * *$ & $0.83 * *$ & $0.66 * *$ & $0.28 *$ \\
\hline
\end{tabular}

$* p=0.007, * * p<0.001$ 


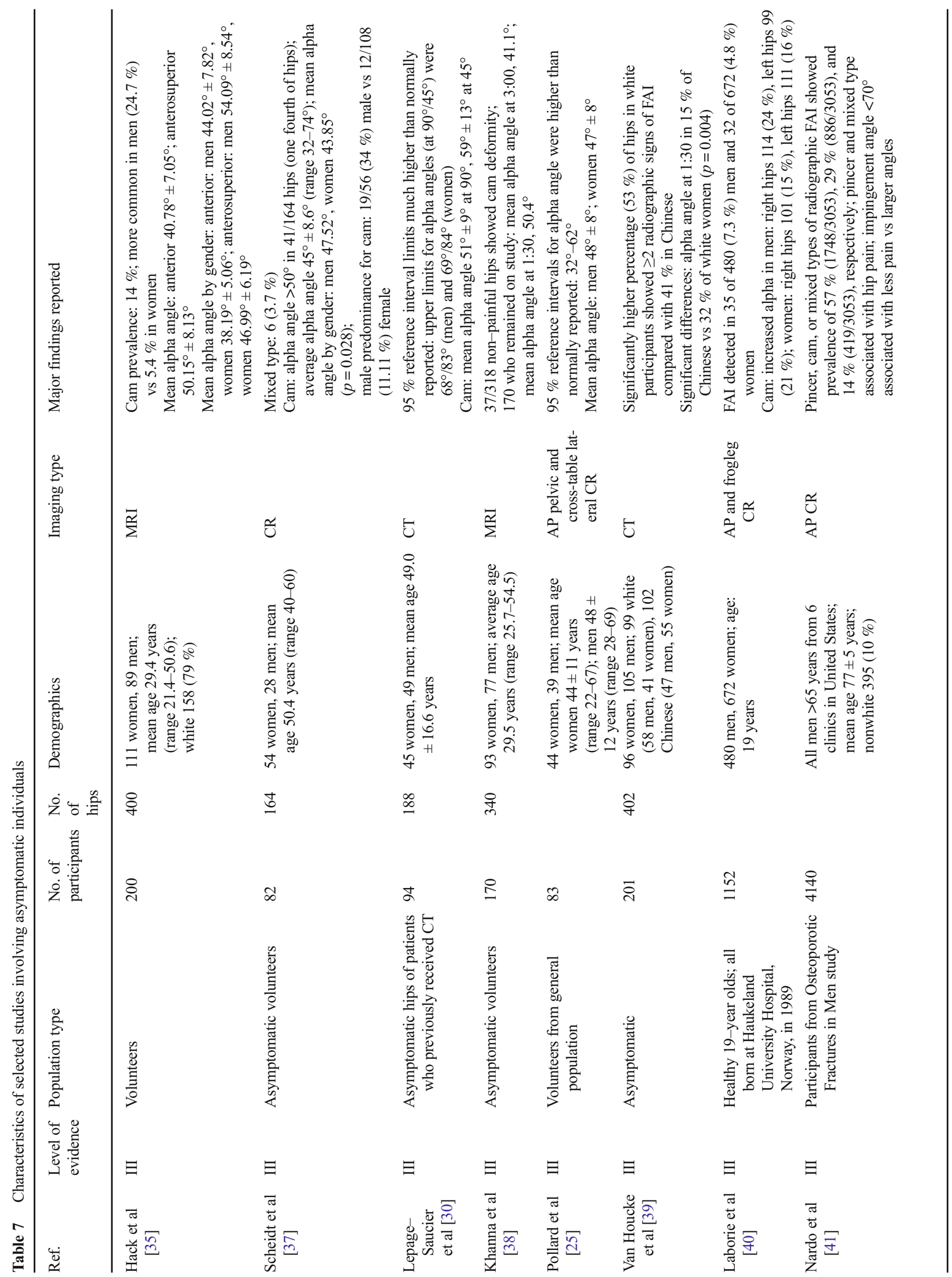




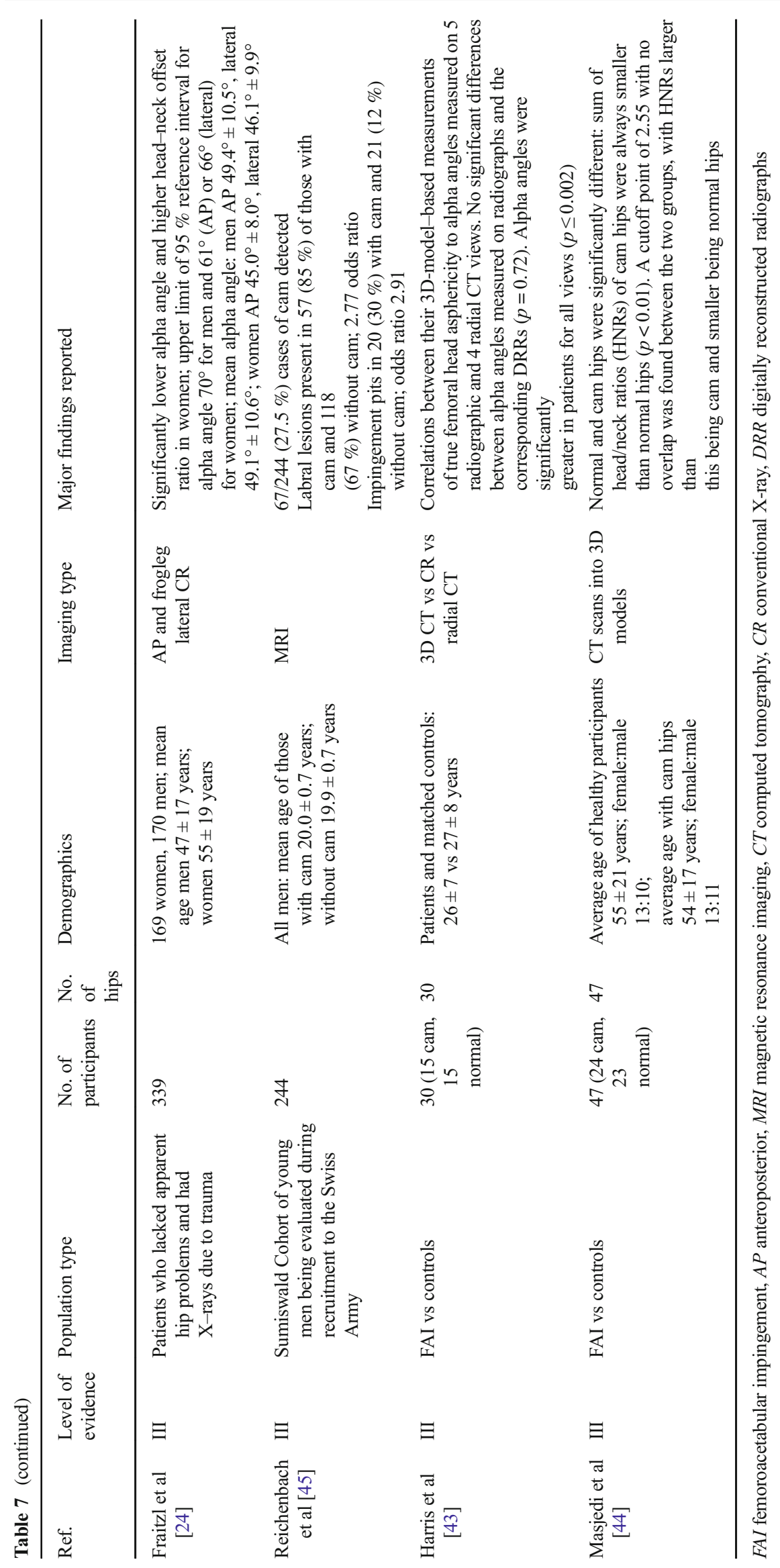


reproducible identification of cam lesions $[19,34,43,49$, 59-61]. Clinical applications for the 3D imaging protocol reported here include the following:

(a) Accurate spatial visualization of cam deformity and hip morphology [62]

(b) Improved diagnosis and monitoring through the use of quantitative 3D morphometric assessment incorporating $\alpha^{\circ}$ and $\Omega^{\circ}$ measurements [63]

(c) Creation of dynamic virtual simulations for preoperative range of motion (ROM) simulation and identification of impingement areas [64]

(d) Provides a tool for standardizing and reducing variability in large-scale and clinical research [59].

This study has several limitations. First, our reference values were derived from a limited sample of 188 hips. Second, defining a normal sample population is an ambitious objective. Third, selecting a protocol for this study may be subject to several biases: Specifically, our participants were not selected from healthy volunteers. In addition, we used patient survey information to exclude hip pathology but did not perform a clinical hip examination. However, we prospectively included patients presenting for nonorthopedic pathology and excluded all patients with any reported history of hip pathology or symptoms. Additionally, we excluded any patients with signs of hip pathology on CT so that our cohort comprised asymptomatic individuals only. Fourth, this study did not include correlation of $3 \mathrm{D} \alpha^{\circ}$ measurements and traditional manual CT measurements; such comparison between 2D and 3D CT methods would be useful but was not an objective of our study, and the software used for this analysis had already been validated for this purpose.

To develop more generalizable reference intervals, larger individual cohort studies with more varied demographics are needed. Further investigations are also needed to incorporate 3D measurements of the acetabulum for a complete picture of hip biomechanics in cases of FAI.

\section{Conclusion}

Cam-type morphology is a 3D deformity. Single 2D measurements of the $\alpha^{\circ}$ should be viewed with caution, as they may not provide a true estimate of the magnitude of the deformity. The $\Omega^{\circ}$ obtained with 3D imaging contributes to a better understanding and characterization of the FHN junction by defining the radial extension and location of cam morphology.

Reference intervals of hip morphometric measurements in asymptomatic individuals were beyond commonly used thresholds, suggesting the need for revisiting the current parameters used in the diagnosis of cam and FAI, specifically by acknowledging that the $\alpha^{\circ}$ alone is an insufficient measure by which to appreciate cam-type morphotype and that its thresholds depend on sex and measurement locations.

Acknowledgments The authors would like to thank José Roquette, João Sá, Isabel Vaz, and Pedro Patrício for their continuing and enthusiastic support toward clinical research at Hospital da Luz, and Rúben Teixeira, Ana Filipa Graça, Rogério Lopes, Diogo Corrente, João Novo, and Tiago Castela for their efforts toward optimizing technical issues and providing patient care

The scientific guarantor of this publication is Prof. Dr. José Roquette, $\mathrm{MD} \mathrm{PhD}$. The authors of this manuscript declare no relationships with any companies, whose products or services may be related to the subject matter of the article. The authors state that this work has not received any funding. One of the authors has significant statistical expertise; however no complex statistical methods were necessary for this paper. Institutional Review Board (Hospital da Luz Ethics Committee) approval was obtained and written informed consent was obtained from all participants in this study.

\section{References}

1. Tibor LM, Leunig M (2012) The pathoanatomy and arthroscopic management of femoroacetabular impingement. Bone Joint Res 1:245-257

2. Agricola R, Heijboer MP, Bierma-Zeinstra SMA et al (2013) Cam impingement causes osteoarthritis of the hip: a nationwide prospective cohort study (CHECK). Ann Rheum Dis 72:918-923

3. Glyn-Jones S, Palmer AJR, Agricola R, et al (2015) Osteoarthritis. Lancet 1-12. doi: 10.1016/S0140-6736(14)60802-3

4. Tannast M, Goricki D, Beck M et al (2008) Hip damage occurs at the zone of femoroacetabular impingement. Clin Orthop Relat Res 466:273-280

5. Frank JM, Harris JD, Erickson BJ, et al (2015) Prevalence of Femoroacetabular Impingement Imaging Findings in Asymptomatic Volunteers: A Systematic Review. YJARS 1-6. doi: 10.1016/j.arthro.2014.11.042

6. Mascarenhas VV, Rego P, Dantas P et al (2016) Imaging prevalence of femoroacetabular impingement in symptomatic patients, athletes, and asymptomatic individuals: a systematic review. Eur J Radiol 85:73-95

7. Tannast M, Siebenrock KA, Anderson SE (2007) Femoroacetabular impingement: radiographic diagnosis-what the radiologist should know. AJR Am J Roentgenol 188:1540-1552

8. Clohisy JC (2008) A systematic approach to the plain radiographic evaluation of the young adult hip. J Bone Joint Surg(Am) 90:47

9. Clohisy JC, Carlisle JC, Trousdale R et al (2008) Radiographic evaluation of the hip has limited reliability. Clin Orthop Relat Res 467:666-675

10. Barton C, Salineros MJ, Rakhra KS, Beaulé PE (2010) Validity of the alpha angle measurement on plain radiographs in the evaluation of cam-type femoroacetabular impingement. Clin Orthop Relat Res 469:464-469

11. Pfirrmann CWA, Mengiardi B, Dora C et al (2006) Cam and pincer femoroacetabular impingement: characteristic MR arthrographic findings in 50 patients. Radiology 240:778-785

12. Beaulé PE, Zaragoza EJ, Motamedi K et al (2005) Threedimensional computed tomography of the hip in the assessment of femoroacetabular impingement. J Orthop Res 23:1286-1292

13. Domayer SE, Ziebarth K, Chan J et al (2011) Femoroacetabular cam-type impingement: diagnostic sensitivity and specificity of radiographic views compared to radial MRI. Eur J Radiol 80:805-810 
14. Dudda M, Albers C, Mamisch TC et al (2008) Do normal radiographs exclude asphericity of the femoral head-neck junction? Clin Orthop Relat Res 467:651-659

15. Rakhra KS, Sheikh AM, Allen D, Beaulé PE (2008) Comparison of MRI alpha angle measurement planes in femoroacetabular impingement. Clin Orthop Relat Res 467:660-665

16. Tannast M, Kubiak-Langer M, Langlotz F et al (2006) Noninvasive three-dimensional assessment of femoroacetabular impingement. J Orthop Res 25:122-131

17. Nötzli HP, Wyss TF, Stoecklin CH et al (2002) The contour of the femoral - junction as a predictor for the risk of anterior impingement. J Bone Joint Surg- Br Vol 84:556-560

18. Nelson AE, Stiller JL, Shi XA et al (2015) Measures of hip morphology are related to development of worsening radiographic hip osteoarthritis over 6 to 13 year follow-up: the Johnston county osteoarthritis project. Osteoarthritis Cartilage / OARS, Osteoarthritis Res Soc. doi:10.1016/j.joca.2015.10.007

19. Milone MT, Bedi A, Poultsides L et al (2013) Novel CT-based three-dimensional software improves the characterization of Cam morphology. Clin Orthop Relat Res 471:2484-2491

20. Lohan DG, Seeger LL, Motamedi K, et al (2009) Cam-type femoral-acetabular impingement: is the alpha angle the best MR arthrography has to offer? Skeletal Radiol

21. Sutter R, Dietrich TJ, Zingg PO, Pfirrmann CWA (2012) How useful is the alpha angle for discriminating between symptomatic patients with cam-type femoroacetabular impingement and asymptomatic volunteers? Radiology 264:514-521

22. Nouh MR, Schweitzer ME, Rybak L, Cohen J (2008) Femoroacetabular impingement: Can the alpha angle Be estimated? Am J Roentgenol 190:1260-1262

23. Gosvig KK, Jacobsen S, Sonne-Holm S et al (2010) Prevalence of malformations of the hip joint and their relationship to sex, groin pain, and risk of osteoarthritis: a population-based survey. J Bone Joint Surg Am 92:1162-1169

24. Fraitzl CR, Kappe T, Pennekamp F et al (2012) Femoral - offset measurements in 339 subjects: distribution and implications for femoroacetabular impingement. Knee Surg Sports Traumatol Arthrosc 21:1212-1217

25. Pollard TCB, Villar RN, Norton MR et al (2010) Femoroacetabular impingement and classification of the cam deformity: the reference interval in normal hips. Acta Orthop 81:134-141

26. Ross JR, Larson CM, Adeoyo $\mathrm{O}$ et al (2014) Residual deformity is the most common reason for revision Hip arthroscopy: a threedimensional CT study. Clin Orthop Relat Res 473:1388-1395

27. Rego PRA, Mascarenhas V, Oliveira FS, et al (2015) Morphologic and angular planning for cam resectionin femoro-acetabular impingement: value of the omega angle. International Orthopaedics (SICOT) 1-7. doi: 10.1007/s00264-015-3053-7

28. Cvetanovich GL, Harris JD, Erickson BJ et al (2015) Revision Hip arthroscopy: a systematic review of diagnoses, operative findings, and outcomes. Arthroscopy 31:1382-1390

29. Christensen CP, Althausen PL, Mittleman MA, et al (2003) The nonarthritic hip score: reliable and validated. Clin Orthop Relat Res 75-83. doi: 10.1097/01.blo.0000043047.84315.4b

30. Lepage-Saucier M, Thiéry C, Larbi A et al (2014) Femoroacetabular impingement: normal values of the quantitative morphometric parameters in asymptomatic hips. Eur Radiol 24:1707-1714

31. Röling MA, Visser MI, Oei EHG et al (2015) A quantitative noninvasive assessment of femoroacetabular impingement with CTbased dynamic simulation-cadaveric validation study. BMC Musculoskelet Disord 16:50

32. Klenke FM, Hoffmann DB, Cross BJ, Siebenrock KA (2014) Validation of a standardized mapping system of the hip joint for radial MRA sequencing. Skelet Radiol. doi:10.1007/s00256-014-2026-Z
33. Philippon MJ, Stubbs AJ, Schenker ML et al (2007) Arthroscopic management of femoroacetabular impingement: osteoplasty technique and literature review. Am J Sports Med 35:1571-1580

34. Audenaert EA, Baelde N, Huysse W et al (2011) Development of a three-dimensional detection method of cam deformities in femoroacetabular impingement. Skelet Radiol 40:921-927

35. Hack K, Di Primio G, Rakhra K, Beaulé PE (2010) Prevalence of cam-type femoroacetabular impingement morphology in asymptomatic volunteers. J Bone Joint Surg 92:2436-2444

36. Kang ACL, Gooding AJ, Coates MH et al (2010) Computed tomography assessment of Hip joints in asymptomatic individuals in relation to femoroacetabular impingement. Am J Sports Med 38:1160-1165

37. Scheidt RB, Galia CR, Diesel CV et al (2014) Prevalence of radiographic markers of femoroacetabular impingement in asymptomatic adults. Rev Col Bras Cir 41:36-42

38. Khanna V, Caragianis A, DiPrimio G et al (2014) Incidence of Hip pain in a prospective cohort of asymptomatic volunteers: is the Cam deformity a risk factor for Hip pain? Am J Sports Med 42:793-797

39. Van Houcke J, Yau WP, Yan CH et al (2015) Prevalence of radiographic parameters predisposing to femoroacetabular impingement in young asymptomatic chinese and white subjects. J Bone Joint Surg Am 97:310-317

40. Laborie LB, Lehmann TG, Engesæter I et al (2013) Is a positive femoroacetabular impingement test a common finding in healthy young adults? Clin Orthop Relat Res 471:2267-2277

41. Osteoporotic Fractures in Men (MrOS) Research Group, Nardo L, Parimi N et al (2015) Femoroacetabular impingement: prevalent and often asymptomatic in older Men: the osteoporotic fractures in Men study. Clin Orthop Relat Res. doi:10.1007/s11999-015-4222-0

42. Reichenbach S, Leunig M, Werlen S et al (2011) Association between cam-type deformities and magnetic resonance imagingdetected structural hip damage: a cross-sectional study in young men. Arthritis Rheum 63:4023-4030

43. Harris MD, Kapron AL, Peters CL, Anderson AE (2014) Correlations between the alpha angle and femoral head asphericity: implications and recommendations for the diagnosis of cam femoroacetabular impingement. Eur J Radiol 83:788-796

44. Masjedi M, Marquardt CS, Drummond IMH et al (2012) Cam type femoro-acetabular impingement: quantifying the diagnosis using three dimensional - ratios. Skelet Radiol. doi:10.1007/s00256-012-1459-5

45. Reichenbach S, Jüni P, Werlen S et al (2010) Prevalence of camtype deformity on hip magnetic resonance imaging in young males: a cross-sectional study. Arthritis Care Res 62:1319-1327

46. Laborie LB, Lehmann TG, Engesaeter IO et al (2011) Prevalence of radiographic findings thought to be associated with femoroacetabular impingement in a population-based cohort of 2081 healthy young adults. Radiology 260:494-502

47. de Bruin F, Reijnierse M, Farhang-Razi V, Bloem JL (2013) Radiographic signs associated with femoroacetabular impingement occur with high prevalence at all ages in a hospital population. Eur Radiol 23:3131-3139

48. Siebenrock KA, Wahab KHA, Werlen S, et al (2004) Abnormal extension of the femoral head epiphysis as a cause of cam impingement. Clin Orthop Relat Res 54-60

49. Khan O, Witt J (2014) Evaluation of the magnitude and location of Cam deformity using three dimensional CT analysis. Bone Joint $\mathrm{J}$ 96-B:1167-1171

50. Sutter R, Dietrich TJ, Zingg PO, Pfirrmann CWA (2012) Femoral antetorsion: comparing asymptomatic volunteers and patients with femoroacetabular impingement. Radiology 263:475-483

51. Ricciardi BF, Fields K, Kelly BT et al (2014) Causes and risk factors for revision hip preservation surgery. Am J Sports Med 42:2627-2633

52. Ito K, Minka-II MA, Leunig M et al (2001) Femoroacetabular impingement and the cam-effect. J Bone Joint Surg 83:171-176 
53. Yanke AB, Khair MM, Stanley R et al (2015) Sex differences in patients with CAM deformities with femoroacetabular impingement: 3-dimensional computed tomographic quantification. Arthroscopy. doi:10.1016/j.arthro.2015.06.007

54. Tannenbaum EP, Zhang P, Maratt JD et al (2015) A computed tomography study of gender differences in acetabular version and morphology: implications for femoroacetabular impingement. Arthrosc: J Arthrosc Relat Surg 31:1247-1254

55. Ross JR, Nepple JJ, Philippon MJ et al (2014) Effect of changes in pelvic tilt on range of motion to impingement and radiographic parameters of acetabular morphologic characteristics. Am J Sports Med 42:2402-2409

56. Harris MD, Datar M, Whitaker RT et al (2013) Statistical shape modeling of cam femoroacetabular impingement. J Orthop Res 31:1620-1626

57. Masjedi M, Mandalia R, Aqil A, Cobb J (2014) Validation of the "FeMorph" software in planning cam osteochondroplasty by incorporating labral morphology. Computer Methods in Biomechanics and Biomedical Engineering 1-7. doi: 10.1080/10255842.2014.986654

58. Steppacher SD, Tannast M, Werlen S, Siebenrock KA (2008) Femoral morphology differs between deficient and excessive acetabular coverage. Clin Orthop Relat Res 466:782-790
59. Xia Y, Fripp J, Chandra SS, et al (2015) Automated 3D quantitative assessment and measurement of alpha angles from the femoral junction using MR imaging. Physics in Medicine \& Biology 76017616. doi: 10.1088/0031-9155/60/19/7601

60. Dandachli W, Islam SU, Liu M et al (2009) Three-dimensional CT analysis to determine acetabular retroversion and the implications for the management of femoro-acetabular impingement. J Bone Joint Surg - Bri Vol 91:1031

61. Larson CM, Moreau-Gaudry A, Kelly BT et al (2014) Are normal hips being labeled as pathologic? a CT-based method for defining normal acetabular coverage. Clin Orthop Relat Res 473:1247-1254

62. Heyworth BE, Dolan MM, Nguyen JT et al (2012) Preoperative three-dimensional CT predicts intraoperative findings in Hip arthroscopy. Clin Orthop Relat Res 470:1950-1957

63. Kang RW, Yanke AB, Orias AE et al (2012) Emerging ideas: novel 3-D quantification and classification of Cam lesions in patients with femoroacetabular impingement. Clin Orthop Relat Res 471:358-362

64. Kuhn AW, Ross JR, Bedi A (2015) Three-dimensional imaging and computer navigation in planning for hip preservation surgery. Sports Med Arthrosc 23:e31-e38 